\title{
From the President
}

\author{
David Pankratz \\ Loyola University Chicago
}

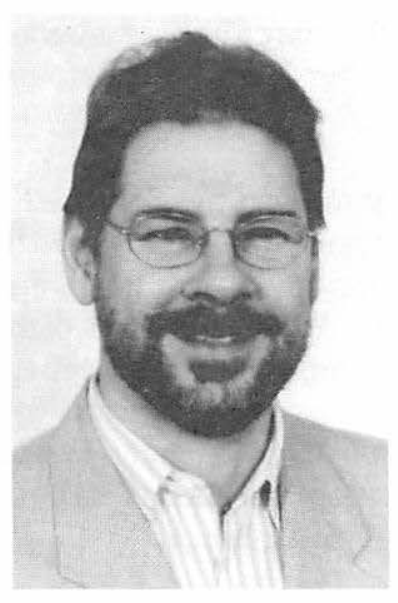

In my previous column I wrote about the importance of having our work with technology both understood and recognized. This can be particularly critical for faculty coming up for tenure, but it is also important for those of us who work with technologyon a daily basis and yet may find ourselves startled by the degree to which our colleaguesand supervisors lack clarityabout the manyactivities we perform.

We have now completed a statement to address these concerns. This is a collective "we," including Peter Liddell (President Elect), myself, the otherIALLTBoard members, the Council, and you, the members at large, through your responses to a survey conducted in early 2002. The document is entitled the "IALLT Statement of Professional Responsibilities." It establishes broad but clear guidelines on the work of language technology professionals. It will serve to help formulate job descriptions, establish evaluation standards, and generallyeducateaboutour manyjobresponsibilities. Without going into detail, I'd like to mention that the statement categorizes our work into three main areas: 1) Research, 2) Administration, and 3) Liaison. Does that whet your appetite to learn more? I hope so! I encourage you to read through this document carefully to see to what extent it defines your work, and then make practical use of the content. It should prove invaluable for the re-writing of job descriptions and educating administrators about our work, for example. Obviously, it cannot describe anyone person's job, and nobody can perform all of the tasks listed, but therein liesits strength. The statement can be found at the iallt.org website, under About IALLT, Official Documents, and on page 19 of this issue of the IALLT Journal.

Another recent project of the IALLT Board and Council was to establish a means by which up-and-coming IALLT'ers can be introduced to our organization. Because our biennial IALLT Conference serves in many ways as the heart and soul of the organization, what better way to support new people than by offering an award to offset the cost of attending the conference? 
We have created the "IALLTGraduate Student Conference Award," intended to help fund needy graduate students who would like to attend our conference. We recognize that graduate students are not the only people in need of such support, but they were chosen as a target group due to the surge of individuals who are becoming professionally qualified in instructional technology and related fields. Of course no award can be given without funding(!), so we have also inaugurated a campaign to accept donations from both corporations and individuals to build this fund. Because IALLT is now registered as a tax-exempt501 (c) (3) organization, donations are taxdeductible to the extent of the law. Please considerdonating to the organization and thereby lending a hand to new members! Details can be found at the website, About IALLT.

Your Board and Council have been busyin other ways. On June 2022 we held our Summer Leadership Meeting (SLM), attended by over 20 members of the Board and Council and several membersat-large. The meeting was held in lovely Ann Arbor, home of the University of Michigan, site of our next conference. The meetings were very productive. Some key topics discussed were member services, digital initiatives, conference planning, our new website, financial considerations of the organization, affiliations with other associations, and the strengthening of regional groups.

One thing that stands out in the minds of all who attended the SLM is how nice the campus at "UMich" and the cityof Ann Arbor will be for the hosting of our conference nextyear. For example, when they passed out a list of $100+$ restaurants within walking distance of campus, I thought they were exaggerating, but they weren't! I look forward to seeingyou there for IALLT 2003, June 17-21! It promises to be fantastic conference, and as most of you know, it is the premier event for educating those responsible for the quality of language technologyservices.

As I write this column, once again the global economy appears to be shaky, and political events around the world continue to be very problematic. In the face of all the uncertainty, I encourage you to persevere in your efforts to "teach the world to sing" in whatever languages you support or teach. Language learning is key, not only because it allows direct communication in ways not otherwise possible, but also because it fosters cross-culturalunderstandingand tolerance. Whatever your contribution to these efforts, I applaud yourworkand persistence-and that of yourcolleaguesand students.

I'm happy to hear from you anytime. Myemail is dpankra@luc.edu 